\title{
A Novel Signal-Amplified Immunoassay for the Detection of C-Reactive Protein Using HRP-Doped Magnetic Nanoparticles as Labels with the Electrochemical Quartz Crystal Microbalance as a Detector
}

\author{
Ning Gan, ${ }^{1}$ Ping Xiong, ${ }^{1}$ Ji Wang, ${ }^{2}$ Tianhua Li, ${ }^{1}$ Futao Hu, ${ }^{1}$ Yuting Cao, ${ }^{1}$ and Lei Zheng ${ }^{3}$ \\ ${ }^{1}$ The State Key Laboratory Base of Novel Functional Materials and Preparation Science, \\ Faculty of Material Science and Chemical Engineering, Ningbo University, Ningbo 315211, China \\ ${ }^{2}$ Faculty of Mechanical Engineering and Mechanics, Ningbo University, Ningbo 315211, China \\ ${ }^{3}$ Department of Laboratory Medicine, Nanfang Hospital, Southern Medical University, Guangzhou, Guangdong 510515, China
}

Correspondence should be addressed to Ning Gan; hcchcnc@126.com

Received 10 August 2012; Revised 6 January 2013; Accepted 9 January 2013

Academic Editor: Antonio Ruiz Medina

Copyright (c) 2013 Ning Gan et al. This is an open access article distributed under the Creative Commons Attribution License, which permits unrestricted use, distribution, and reproduction in any medium, provided the original work is properly cited.

A novel horseradish peroxidase- (HPR-) doped magnetic core-shell $\mathrm{Fe}_{3} \mathrm{O}_{4} @ \mathrm{SiO}_{2} @ \mathrm{Au}$ nanocomposites (Fe-Au MNPs) were employed on immunoassay for the determination of C-reactive protein (CRP) based on a electrochemical quartz crystal microbalance detector (EQCM). Firstly, the secondary CRP antibody and HRP were both immobilized on the Fe-Au MNPs (Fe-Au MNPs-anti-CRP2/HRP) as a signal tag. Secondly, the above tag and the primary antibody (anti-CRP1) in the bottom of 96-well microtiter plate were employed to conjugate with a serial of CRP concentrations to produce a sandwich immunocomplex. Thirdly, the immunocomplex solution was subsequently exposed to $3,3^{\prime}$-diaminobenzidine (DAB) in the presence of $\mathrm{H}_{2} \mathrm{O}_{2}$, resulting in an insoluble product. When the precipitation solution was dripped on EQCM, it can achieve a decrease of frequency of crystal $(\Delta f)$. The amount of $\Delta f$ was proportional to (CRP) from 0.003 to $200 \mathrm{ng} \mathrm{mL}^{-1}$ with a low detection limit of $1 \mathrm{pg} \mathrm{mL}^{-1}$. Compared with the enzyme-linked immunosorbent assay (ELISA), the immunoassay shows greatly improved sensitivity due to the significant amount of HRP labeled on signal tag. It also has good specificity and low sample consumption, which is expected to be a benefit for the CRP screening in early diagnosis of cardiovascular disease.

\section{Introduction}

Cardiovascular disease (CVD) is a highly lethal disease. Thus, there must be excellent candidates for the rapid and inexpensive diagnosis of CVD [1]. C-reactive protein (CRP) is the most widely used as a CVD marker for the early diagnosis of the disease [2]. Recently, the usual way to predict CVD is detecting the concentration of CRP in serum. Ultrasensitive methodologies for detecting free CRP in human serums are required. The most common approaches in analyzing CRP are enzyme-linked immunosorbent assay (ELISA), immunofluorescence, and so forth [3]. However, most of usual methods are time consuming, labor intensive, and hazardous to health or require highly qualified personnel and sophisticated instrumentation [4-6].
Electrochemical detection is attracting more attention due to its low cost, wide dynamic concentration response range, versatility, simple instrumentation, stability, and high sensitivity [7]. Moreover, it is not affected by the sample components that might interfere with spectroscopic detection, such as particles, chromophores, and fluorophores [8]. Thus, the measurements can be made on blood samples without interference from red blood cells, hemoglobin, or other proteins. Among the electrochemical sensors, the electrochemical immunoassays that capitalize on the selectivity of antigen-antibody reactions have excellent detection limits. Quartz is one member of a family of crystals that experience the piezoelectric effect. The quartz crystal microbalance $(\mathrm{QCM})$ can acquire an ultratrace mass per 
unit area by measuring the change in frequency of a quartz crystal resonator $[9,10]$. The QCM typically consists of a thin disk of an AT-cut quartz crystal with circular metal electrodes on both surfaces. The QCM has been widely used to monitor the thickness change of film deposition according to the Sauerbrey equation [9] which relates the decrease in frequency $\Delta f$ of the QCM and the added mass $\Delta m$ of the thin film rigidly coupled to the crystal surface: $\Delta f=$ $-\left(2 f_{0}^{2} / A \sqrt{\rho_{q} \mu_{q}}\right) \Delta m$, where $f_{0}$ is the crystal fundamental frequency, $A$ is the piezoelectric active area, and $\rho_{q}$ and $\mu_{q}$ are the density $\left(2650 \mathrm{kgm}^{-3}\right)$ and the shear modulus $(2.94$ $\times 10^{10} \mathrm{Nm}^{-2}$ ) of the AT-cut quartz, respectively. QCM can also be used to investigate interactions between biomolecules, such as antigen and antibody. By measuring the change of frequency $(\Delta f)$ after the immunocomplex formed on the electrode, the signal can help to analyze the amount of antigen [11]. Furthermore, the QCM immunosensor is also a kind of label-free biosensor in immunoassays. Herein, the electrochemical quartz crystal microbalance (EQCM) was employed as the real-time transducer for detecting CRP in immunoassay.

Antibody immobilization is vital in successful development of an EQCM immunoassay, and the present immobilization methods, such as chemical modification, selfassembly, or physical absorption, are usually quite complex and liable to make the antibody deactivate in real application [12]. So if the antibody modification procedure can be excluded, there will be a good prospect for the method. Moreover, some of the enzyme-catalyzed products in sandwich ELISA were precipitated, so it can be directly measured on EQCM electrode. 3,3'-Diaminobenzidine (DAB) is usually employed as substrate in amplification of signal [13]. The HRP can biocatalyze DAB in the presence of $\mathrm{H}_{2} \mathrm{O}_{2}$, resulting in an insoluble product on the electrode surface, to achieve an obviously decreased frequency. The above detection principle has been widely used in the development of novel EQCM biosensor [14]. If elevating the amount of above insoluble catalyzed precipitates accumulated on EQCM transducers, the sensitivity of the immunoassay can also be greatly improved [15].

Signal amplification is the most important strategy that has been extensively used for the development of ultrasensitive immunoassay [16]. The use of nanomaterials as signal amplifiers is of particular interest in biosensor design, due to their outstanding optical, electronic, and biocompatible performance [17]. In the past decades, magnetic nanoparticles (MNPs) have attracted wide interests due to their unique features, such as good magnetic separation, thermal stabilities, and particle morphology [18]. Thus, MNPs take advantage over the convenient nanoparticles, and they are more suitable for usage in biology and medicine. Furthermore, superparamagnetic iron oxide nanoparticles, such as $\mathrm{Fe}_{3} \mathrm{O}_{4}$ nanoparticles $\left(\mathrm{Fe}_{3} \mathrm{O}_{4} \mathrm{NPs}\right.$ ), have been functionalized with many different biological shells for interaction with biological molecules or cells so as to separate them by a magnetic field [19]. It is well known that nanogold particles (AuNPs) possess the property of high stability and the capacity to combine with amino or mercaptol group in biomolecules.
Thus, combining $\mathrm{Fe}_{3} \mathrm{O}_{4}$ magnetic nanoparticles with silicon dioxide and AuNPs shell $\left(\mathrm{Fe}_{3} \mathrm{O}_{4} @ \mathrm{SiO}_{2} @ \mathrm{Au}\right)$ will have great potential application in biotechnology [20].

The most widely used synthesized method for $\mathrm{Fe}_{3} \mathrm{O}_{4} @ \mathrm{SiO}_{2} @ \mathrm{Au}$ core-shell magnetic nanoparticles was self-assembly. In this method, two kinds of nanoparticles were linked by coupling agent to form a strong chemical bond. The composites became more stable by employing this method because the magnetic particles were coated with a large amount of free amine group $\left(-\mathrm{NH}_{2}\right)$ in the $\mathrm{SiO}_{2}$ shell with 3-aminopropyhriethoxysilane (APTS) which has been found to exhibit a strong binding force to colloid $\mathrm{Au}$. In this study, $\mathrm{Fe}_{3} \mathrm{O}_{4}$ magnetic particles fictionalization of $-\mathrm{NH}_{2}$ was prepared firstly, then AuNPs magnetic composites particles were self-assembled on $\mathrm{Fe}_{3} \mathrm{O}_{4}$ NPs [21]. AuNPs have the capability to bind with the $-\mathrm{SH}$ in the biomolecules. The secondary antibody and HRP can both be immobilized on $\mathrm{Fe}_{3} \mathrm{O}_{4} @ \mathrm{SiO}_{2} @ \mathrm{Au}$ to synthesize the signal tag (Fe-Au MNPsanti-CRP2/HRP). The antibody on the tag can capture CRP in solution, while HRP can catalyze DAB to amplify the change of frequency signal $(\Delta f)$. Thus, the immunoassay for CRP can be acquired.

Herein, CRP in serum is selectively captured by the primary antibody of CRP (anti-CRP1) deposited on the 96-well pore and then recognized by Fe-Au MNPs-anti-CRP2/HRP signal tag. The bound HRP will catalyze the $\mathrm{H}_{2} \mathrm{O}_{2}$-induced oxidation of DAB substrate to form an insoluble precipitation $[22,23]$ on the crystals, thus causing frequency changes $(\Delta f)$ which are proportional to the concentrations of targeting CRP. The main advantage of this enzyme-catalytic precipitation protocol lies in that the accumulation of an insoluble product on the crystals can lead to greatly increased mass changes as reflected by $\Delta f$. It can achieve much higher detection sensitivity than some traditional ELISA methods [24] with mass changes directly originating from the large amount of HRP enzyme-labeled on the magnetic signal tag. In addition, this strategy combines the merits of electrochemical method and traditional ELISA method and smoothes away the cumbersome electrode modification process in electrochemical immunoassay.

\section{Experimental Section}

2.1. Chemicals and Materials. HRP-labeled monoclonal mouse anti-human CRP and CRP test kit were obtained from Sigma and Santa Cruz Co. Ltd. (USA). DAB and HRP (EC 1.11.1.7, RZ > 3.0, $A>250 \mathrm{U} / \mathrm{mg}$ ) were purchased from Aldrich (USA). Tetraethylorthosilicate (TEOS), APTS, hydrogen tetrachloroaurate (III) tetrahydrate $\left(\mathrm{HAuCl}_{4} \cdot 4 \mathrm{H}_{2} \mathrm{O}\right)$, $\mathrm{H}_{2} \mathrm{O}_{2}$, and bovine serum albumin (BSA) were obtained from Sinopharm Group Chem. Re. Co., Ltd. (Shanghai, China). All reagents used were of analytical-reagent grade, and all solutions were prepared with double-deionized water. Phosphate buffer saline (PBS, $0.1 \mathrm{M}$ ) of various $\mathrm{pH}$ was prepared by mixing the stock solutions of $\mathrm{NaH}_{2} \mathrm{PO}_{4}$ and $\mathrm{Na}_{2} \mathrm{HPO}_{4}$. The washing buffer was prepared with $0.02 \mathrm{~mol} / \mathrm{L}$ PBS (pH 7.2) containing 0.5\% BSA, $0.25 \%$ Tween-20, and $0.15 \mathrm{~mol} / \mathrm{L} \mathrm{NaCl}$. 


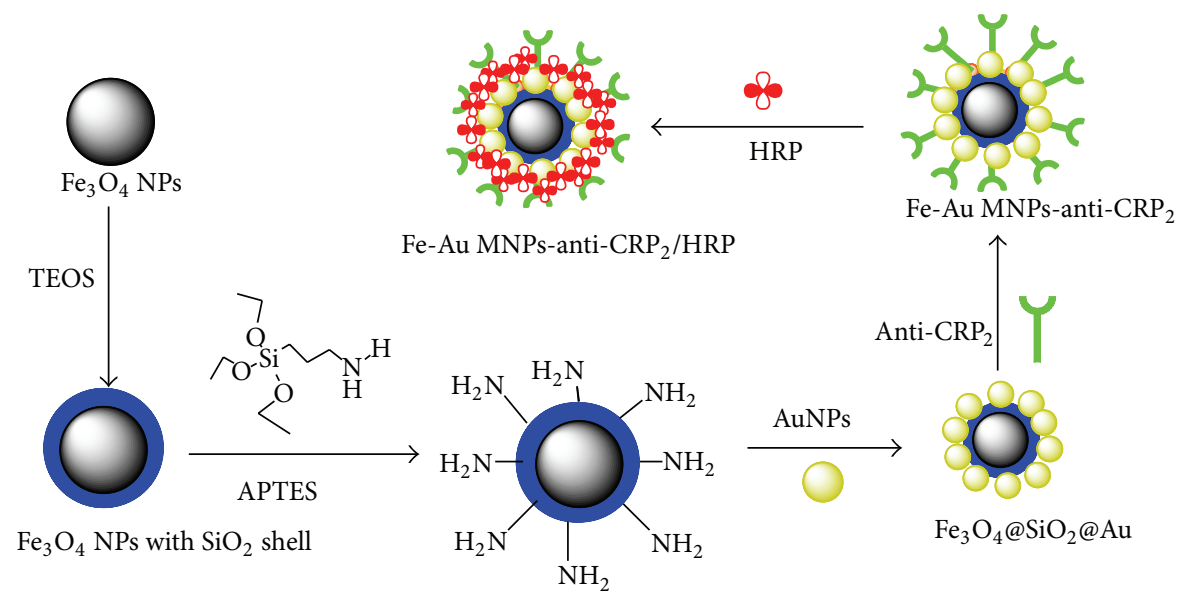

FIgURE 1: Schematic of the preparation of Fe-Au MNPs-anti-CRP2/HRP conjugation.

2.2. Apparatus. CHI 400 A electrochemical analyzer, crystals (9 MHz, gold electrodes), and QCM cell system were bought from CHI Instruments (Shanghai Chenhua Co., Ltd., China), in which the QCM cell consists of a detection cell and $\mathrm{Ag} / \mathrm{AgCl}$ reference electrode and Pt wire counter electrode. The crystals were washed in an ultrasonic cleaner (B2000, Branson Co., Shanghai, China). The morphology of the nanoparticles was characterized by an H-7650 transmission electron microscope (TEM, Hitachi, Japan) and an S3400N scanning electron microscope (SEM, Hitachi, Japan). UVVis spectra were recorded with a TU-1901 spectrophotometer (Beijing Purkinje General Instrument Co., Ltd., China).

2.3. Self-Assembly of Nano-Au on $\mathrm{Fe}_{3} \mathrm{O}_{4}\left(\mathrm{Fe}_{3} \mathrm{O}_{4} @ \mathrm{SiO}_{2} @ A u\right)$. The $\mathrm{Fe}_{3} \mathrm{O}_{4}$ NPs synthesized according to reference (0.3 g) [19] were dispersed in $20 \%$ ethanol $(50 \mathrm{~mL})$ by ultrasonic and APTS $(0.4 \mathrm{~mL})$ was added dropwise. The mixture was stirred at room temperature for $7 \mathrm{~h}$. The desired aminated magnetic particles were afforded as light brown suspension. Uncoated $\mathrm{Fe}_{3} \mathrm{O}_{4}$ was deleted by means of washing the mixture with $0.1 \mathrm{~mol} / \mathrm{L} \mathrm{HCl}$ (six times, $4 \mathrm{~h}$ ). Then the suspension was prepared to $1 \mathrm{~g} / \mathrm{L} \mathrm{Fe}_{3} \mathrm{O}_{4}$ with ethanol. The colloid $\mathrm{Au}(2.5 \mathrm{~g} / \mathrm{L}$, $10 \mathrm{~mL}$ ) was added to the above prepared amination $\mathrm{Fe}_{3} \mathrm{O}_{4}$ NPs $(25 \mathrm{~mL})$ at room temperature with a stirring speed at $170 \mathrm{r} / \mathrm{min}$. After stirring for $12 \mathrm{~h}$, the excess $\mathrm{Fe}_{3} \mathrm{O}_{4}$ NPs were removed by addition of $0.1 \mathrm{~mol} / \mathrm{L} \mathrm{HCl}$, and the precipitate was washed with distilled water until the eluted water became neutral $(\mathrm{pH}=7.0)$. The ratio of $\mathrm{Fe}_{3} \mathrm{O}_{4} @ \mathrm{SiO}_{2}$ and AuNPs $\left(\mathrm{Fe}_{3} \mathrm{O}_{4} @ \mathrm{SiO}_{2} / \mathrm{AuNPs}\right)$ was $1: 1.2$. The concentration of $\mathrm{Fe}_{3} \mathrm{O}_{4} @ \mathrm{SiO}_{2} @ \mathrm{Au}$ was about $2 \mathrm{mg} / \mathrm{mL}$.

\subsection{Preparation of Fe-Au MNPs-Anti-CRP2/HRP Nanobio-} conjugation as Signal Tag. The procedure to prepare $\mathrm{Fe}-\mathrm{Au}$ MNPs-anti-CRP2/HRP was shown in Figure 1. About $1.0 \mathrm{~mL}$ of $\mathrm{Fe}_{3} \mathrm{O}_{4} @ \mathrm{SiO}_{2} @ \mathrm{Au}$ nanoparticles suspension was initially adjusted to $\mathrm{pH} 8.2$ using $\mathrm{Na}_{2} \mathrm{CO}_{3}$, and then $10 \mu \mathrm{L}$ of the original anti-CRP2 $(10 \mu \mathrm{g} / \mathrm{mL})$ was added into the mixture and incubated for $12 \mathrm{~h}$ at $4^{\circ} \mathrm{C}$ with slightly stirring. After magnetic separation, the obtained Fe-Au MNPs-anti-CRP2 conjugates can be easily acquired and then were incubated with $1.5 \mathrm{~mL}$ of $1 \mathrm{mg} / \mathrm{mL}$ HRP for $1 \mathrm{~h}$ to block the nonspecific sites on the uncovered surface of $\mathrm{Fe}_{3} \mathrm{O}_{4} @ \mathrm{SiO}_{2} @ \mathrm{Au}$ nanoparticles. Then also after magnetic separation, the synthesized $\mathrm{Fe}-\mathrm{Au}$ MNPs-anti-CRP2/HRP bioconjugations were present in the precipitation, which can be stored in $2 \mathrm{~mL}$ of $\mathrm{pH} 7.4$ PBS at $4^{\circ} \mathrm{C}$ when not in use.

2.5. Immunoassay Procedures. A schematic representation of the steps used to perform the electrochemical ELISA was shown in Figure 2(a). An anti-CRP precoated polystyrene 96well microtiter plate was incubated with $100 \mu \mathrm{L}$ of different concentrations CRP for $30 \mathrm{~min}$ at $37^{\circ} \mathrm{C}$. After incubation, the wells were washed six times with $\mathrm{pH}$ 7.4 PBS containing $0.05 \%$ (W/V) Tween-20. Then $100 \mu \mathrm{L}$ of Fe-Au MNPs-antiCRP2/HRP conjugations (1:10 dilution with PBS containing $1 \mathrm{wt} . \% \mathrm{BSA}$ ) was pipetted into each well and incubated at $37^{\circ} \mathrm{C}$ for $30 \mathrm{~min}$. After the wells were rinsed, $100 \mu \mathrm{L}$ of $10 \mathrm{mmol} / \mathrm{L}$ $\mathrm{DAB}$ and $3 \mathrm{mmol} / \mathrm{L}_{2} \mathrm{O}_{2}$ mixture solution were added to each well, and the enzymatic reaction was allowed to proceed for $10 \mathrm{~min}$ at $37^{\circ} \mathrm{C}$. The resulting reaction solution $(20 \mu \mathrm{L})$ was dropped onto EQCM electrode with $5 \mu \mathrm{L}$ PBS ( $\mathrm{pH} 7.0$, Figures 2(b) and 2(c)). After each detection, the electrode was instantaneously washed with PBS solution for 5 times to remove the precipitation solution. Because the precipitation by DAB was dropped on the electrode, it can be easily washed away; thus, the EQCM detector can be renewed.

\section{Results and Discussion}

3.1. Characterization of Fe-Au MNPs-Anti-CRP2/HRP Nanobioconjugation. The core-shell $\mathrm{Fe}_{3} \mathrm{O}_{4} @ \mathrm{SiO}_{2} @ \mathrm{Au}$ nanoparticle was used to label anti-CRP2 and HRP. The SEM images showed that both amination $\mathrm{Fe}_{3} \mathrm{O}_{4}-\mathrm{NH}_{2}$ and $\mathrm{Fe}_{3} \mathrm{O}_{4} @ \mathrm{SiO}_{2} @ \mathrm{Au}$ nanoparticles were of well spherical structure and preferable monodispersity in size. The average diameter of $\mathrm{Fe}_{3} \mathrm{O}_{4}-\mathrm{NH}_{2}$ nanoparticles and core-shell 


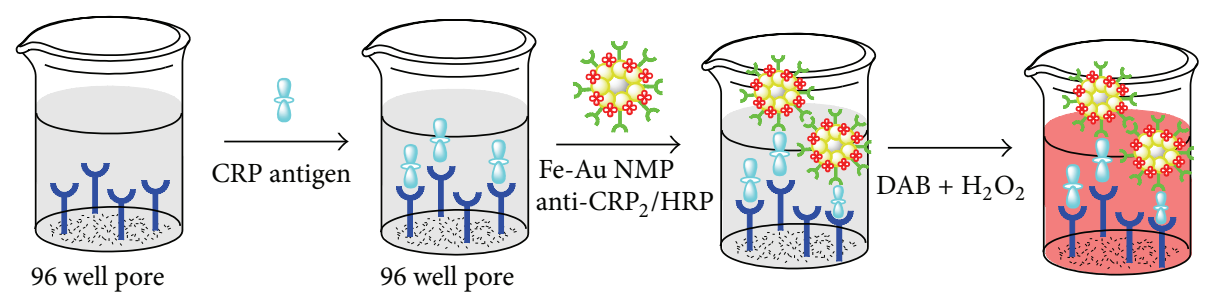

(a)

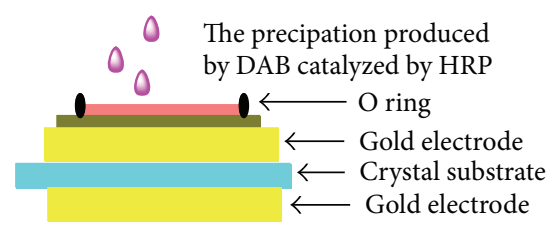

(b)

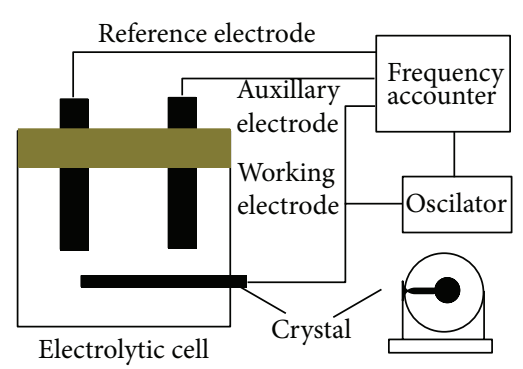

(c)

FIGURE 2: Schematic of the preparation of Fe-Au MNPs-anti-CRP2/HRP conjugation and the immunoassay procedure with the application of Fe-Au MNPs-anti-CRP2/HRP as the signal tag (a) and the EQCM's measurement steps (b) and detection system (c).

$\mathrm{Fe}_{3} \mathrm{O}_{4} @ \mathrm{SiO}_{2} @ \mathrm{Au}$ nanoparticles were about $100 \mathrm{~nm}$ (Figure 3(a)) and $120 \mathrm{~nm}$ (Figure 3(b)), respectively, demonstrating that the Au shell was about $10 \mathrm{~nm}$ thick. As shown in Figure 3(c), the SEM spectrum of Fe-Au MNPs-antiCRP2/HRP showed the particle was homogeneous and its diameter was enhanced to $250 \mathrm{~nm}$. These proved that the large biomolecule of HRP and anti-CRP2 can be immobilized on $\mathrm{Fe}_{3} \mathrm{O}_{4} @ \mathrm{SiO}_{2} @ \mathrm{Au}$ nanoparticles. Once an external magnetic field was applied, the complex was attracted quickly toward the magnet and redispersed into water while removing the magnet, indicating Fe-Au MNPs-anti-CRP2/ HRP signal tag has good paramagnetism (Figure 3(d)).

The magnetic properties of the nanoparticles are illustrated in Figure 4. It can be seen that a small coercivity or remanence existed around room temperature, indicating that the $\mathrm{Fe}_{3} \mathrm{O}_{4} @ \mathrm{SiO}_{2}$ and $\mathrm{Fe}_{3} \mathrm{O}_{4} @ \mathrm{SiO}_{2} @ \mathrm{Au}$ have superparamagnetic properties, which explained the $\mathrm{Fe}_{3} \mathrm{O}_{4} @ \mathrm{SiO}_{2} @ \mathrm{Au}$ could be employed for magnetic separation. The saturation magnetization values for $\mathrm{Fe}_{3} \mathrm{O}_{4} @ \mathrm{SiO}_{2}$ and $\mathrm{Fe}_{3} \mathrm{O}_{4} @ \mathrm{SiO}_{2} @ \mathrm{Au}$ were $3.34 \mathrm{emu} / \mathrm{g}$ and $1.29 \mathrm{emu} / \mathrm{g}$, respectively. The reason for the saturation magnetization value of $\mathrm{Fe}_{3} \mathrm{O}_{4} @ \mathrm{Au}$ being smaller than $\mathrm{Fe}_{3} \mathrm{O}_{4}-\mathrm{NH}_{2}$ is that the former has a larger shell of $\mathrm{Au}$ without magnetic features.

UV-Vis absorption spectrometry was also employed to characterize the nanobioconjugation of Fe-Au MNPs-antiCRP2/HRP. The $\mathrm{Fe}_{3} \mathrm{O}_{4}$ nanoparticles showed no characteristic absorption peak in the examined range from 200 to $650 \mathrm{~nm}$ (Figure 5(a)). When gold nanoparticles were deposited on the surface of $\mathrm{Fe}_{3} \mathrm{O}_{4}$ NPs, a new absorption band centered at $520 \mathrm{~nm}$ resulted from gold nanoparticles was observed (Figure 5(b)), indicating the $\mathrm{Fe}_{3} \mathrm{O}_{4} @ \mathrm{SiO}_{2} @ \mathrm{Au}$ nanoparticles were successfully prepared, which was in good agreement with the results of Lai et al. [20]. After the HRP and anti-CRP molecules being labeled onto the surface of the $\mathrm{Fe}_{3} \mathrm{O}_{4} @ \mathrm{SiO}_{2} @ \mathrm{Au}$ nanoparticles, the obtained Fe-Au MNPsanti-CRP2/HRP nanobioconjugate exhibited two absorption peaks at 280 and $410 \mathrm{~nm}$ [21] (Figure 5(d)). The peak at $520 \mathrm{~nm}$ originated in $\mathrm{Au}$ peaks on the $\mathrm{Fe}_{3} \mathrm{O}_{4} @ \mathrm{SiO}_{2} @ \mathrm{Au}$ nanoparticles. The peak at $280 \mathrm{~nm}$ and $410 \mathrm{~nm}$ was respectively attributed to the absorption of anti-CRP2 and HPR as judged from Figure 5(c). On the basis of the above results, it can be concluded that Fe-Au MNPs-anti-CRP2/HRP nanobioconjugation was successfully prepared.

3.2. The Characterization of Signal Amplification by $\mathrm{Fe}$ Au MNPs-Anti-CRP2/HRP 2 by Different Labels. To clarify the amplification effect of Fe-Au MNPs-anti-CRP2/HRP bioconjugation as the signal tag, we constructed two types of tags, including HRP-anti-CRP2 and Fe-Au MNPs-anti$\mathrm{CRP} 2 / \mathrm{HRP}_{2}$ for comparison. Different concentrations of CRP were used as an example for the evaluation of the signal response. The judgment was based on the slope of frequency change $(\Delta f)$ with the concentration. As shown in Figure 5, the use of $\mathrm{Fe}-\mathrm{Au}$ MNPs-anti-CRP2/ $\mathrm{HRP}_{2}$ as the detection antibody $(\Delta f=24.1 \mathrm{~Hz} / \log C \mathrm{~A}$, Figure 6(a)) exhibited much higher signal response than that of applying HRP-AFP Ab2 $(\Delta f=4.8 \mathrm{~Hz} / \log C$, Figure $6(\mathrm{~b}))$. The sensitivity of the former is about 5 -fold of the latter which meant that the immunosensor by Fe-Au MNPs-anti-CRP2/HRP 2 can generate significant signal amplification than HRP-anti-CRP2. The reason might be that the amount of labeled HRP is much higher in Fe-Au MNPs-anti-CRP2/HRP 2 detection antibody than in HRP-anti-CRP2. When one Fe-Au MNPsanti-CRP2/HRP 2 detection antibody reacted with the antigen, dozens of HRP can catalyze DAB to produce a large amount of precipitate in the present of $\mathrm{H}_{2} \mathrm{O}_{2}$. 


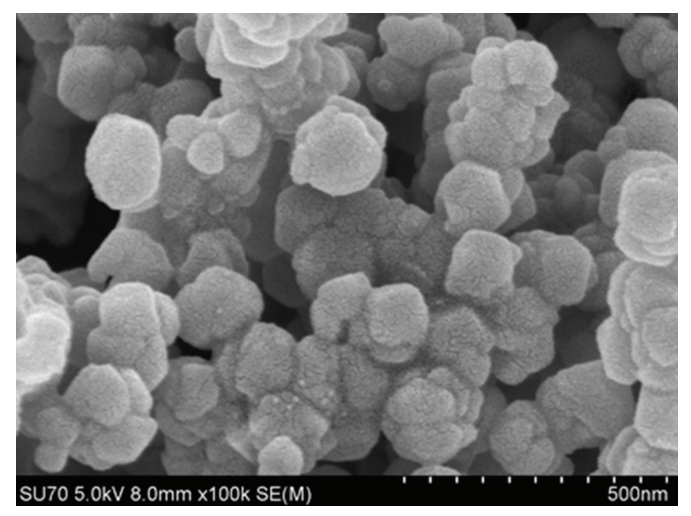

(a)

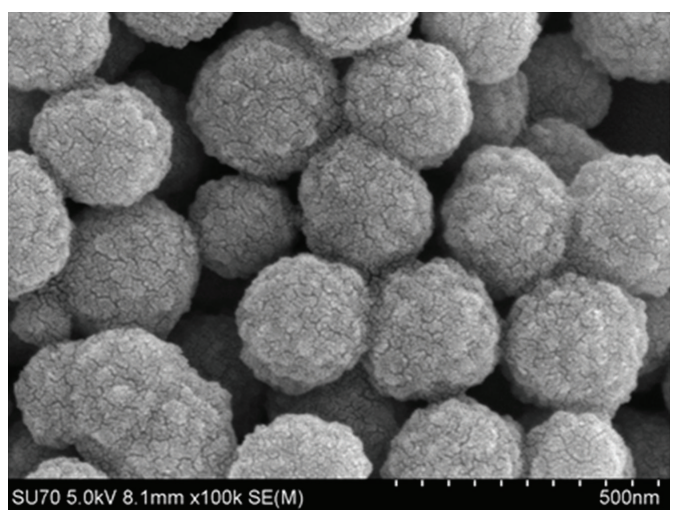

(c)

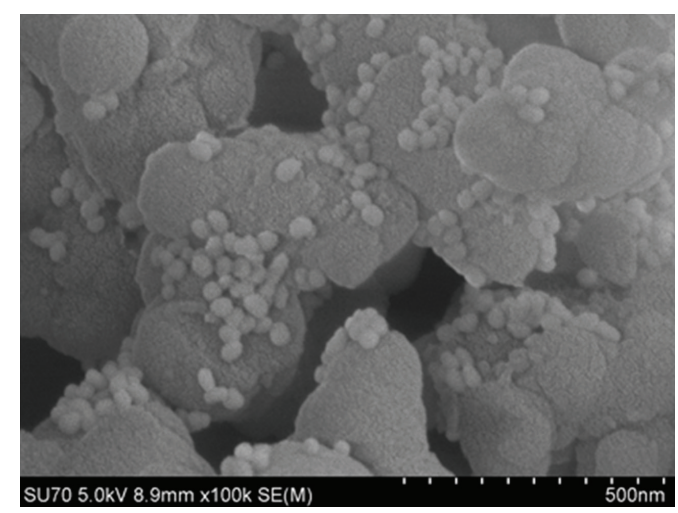

(b)

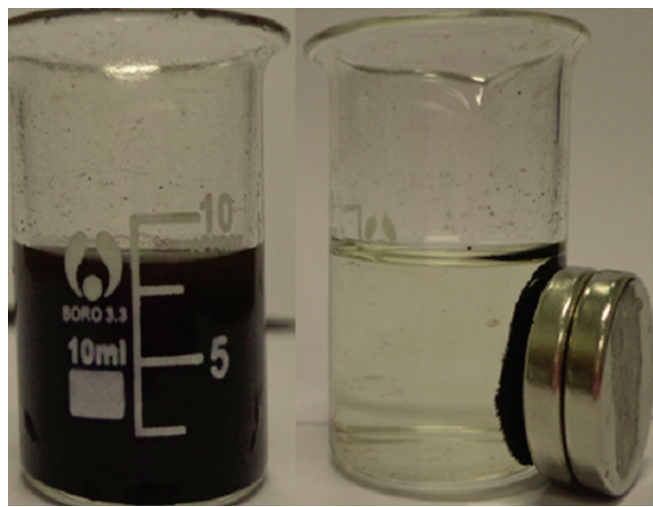

(d)

Figure 3: SEM images of (a) $\mathrm{Fe}_{3} \mathrm{O}_{4} @ \mathrm{SiO}_{2}$, (b) $\mathrm{Fe}_{3} \mathrm{O}_{4} @ \mathrm{SiO}_{2} @ \mathrm{Au}$, (c) Fe-Au MNPs-anti-CRP2/HRP signal tag, (d) c in absence (right) and presence (left) of magnetic field.

3.3. Optimization of Experimental Conditions. The immunoassay conditions such as the amount of the Fe-Au MNPs-antiCRP2/HRP-HRP and DAB on the electrode, $\mathrm{pH}$ of the supporting electrolyte, incubation temperature, and the incubation time can affect the ECL response of the immunosensor.

The concentration of HRP and anti-CPR2 labeled on $\mathrm{Fe}_{3} \mathrm{O}_{4} @ \mathrm{SiO}_{2} @ \mathrm{Au}$ highly influences the performance of FeAu MNPs-anti-CRP2/HRP-HRP signal tag. To obtain a stable and sensitive immunoassay and maintain its precipitation forming ability, the concentration of HPR and anti-CPR2 was, respectively, set as $1 \mu \mathrm{g} / \mathrm{mL}$ and $1 \mathrm{mg} / \mathrm{mL}$. Then mix solution with different volume ratios of HRP and anti-CPR2 was labeled on $\mathrm{Fe}_{3} \mathrm{O}_{4} @ \mathrm{SiO}_{2} @ \mathrm{Au}$ to construct the signal tag for measurement. The results (Figure 7(a)) revealed that HRP and anti-CRP2 solution in the volume ratio of 150:1 was optimal. Further, based on the experimental results, $10 \mu \mathrm{L}$ of Fe-Au MNPs-anti-CRP2/HRP-HRP signal tag composite solution was selected as the optimal amount dropped on the electrode surface.

The concentrations of $\mathrm{H}_{2} \mathrm{O}_{2}$ and $\mathrm{DAB}$ are important parameters that influence the activity of HRP. Using $10.0 \mathrm{ng} \cdot \mathrm{mL}^{-1} \mathrm{CRP}$ as a model, we monitored the effect of concentrations of $\mathrm{H}_{2} \mathrm{O}_{2}$ and DAB on the current response of the electrochemical ELISA. The reduction peak current of the enzymatic oxidation product increased with the increasing concentrations of $\mathrm{H}_{2} \mathrm{O}_{2}$ (Figure 7(b)) and DAB (Figure 7(c)) maintained the maximum value at higher concentrations. Afterward, the enzymatic reaction rate depended on the amount of the labeled HRP. Therefore, the optimal concentrations of $10 \mathrm{mmol} / \mathrm{L}$ for $\mathrm{DAB}$ and $3 \mathrm{mmol} / \mathrm{L}$ for $\mathrm{H}_{2} \mathrm{O}_{2}$ were used for the immunosensor.

The effects of incubation temperature and incubation time on the EQCM response of the immunosensor were also investigated. The results revealed that $\Delta f$ increased with the increase of incubation temperature from 20 to $45^{\circ} \mathrm{C}$ and a maximum $\Delta f$ was obtained at $37^{\circ} \mathrm{C}$. Figure $7(\mathrm{~d})$ shows that $\Delta f$ increased with the increase of incubation time and reached a plateau at $30 \mathrm{~min}$. Therefore, $37^{\circ} \mathrm{C}$ and $30 \mathrm{~min}$ were selected as the optimum incubation temperature and time in this study.

3.4. Analytical Performance. Under the optimal conditions, the electrochemical ELISA was carried out to analyze various concentrations of CRP solution and the EQCM response was recorded. The $\Delta f$ of EQCM response increased with the increasing CRP concentration. The linear range was $0.003 \sim$ $200 \mathrm{ng} / \mathrm{mL}$ with a limit of detection (LOD) of $1 \mathrm{pg} / \mathrm{mL}$.

3.5. Specificity, Reproducibility, and Stability. To evaluate the specificity of the proposed electrochemical ELISA for CRP 


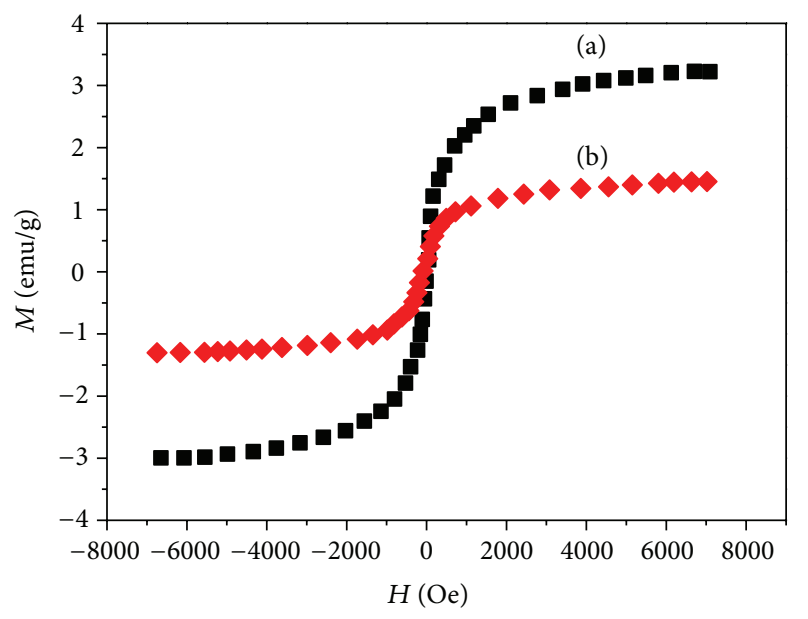

FIgURE 4: Hysteresis loops of magnetic silica nanospheres with (a) $\mathrm{Fe}_{3} \mathrm{O}_{4}-\mathrm{NH}_{2}$ and (b) $\mathrm{Fe}_{3} \mathrm{O}_{4} @ \mathrm{SiO}_{2} @ \mathrm{Au}$ at $300 \mathrm{~K}$, respectively.

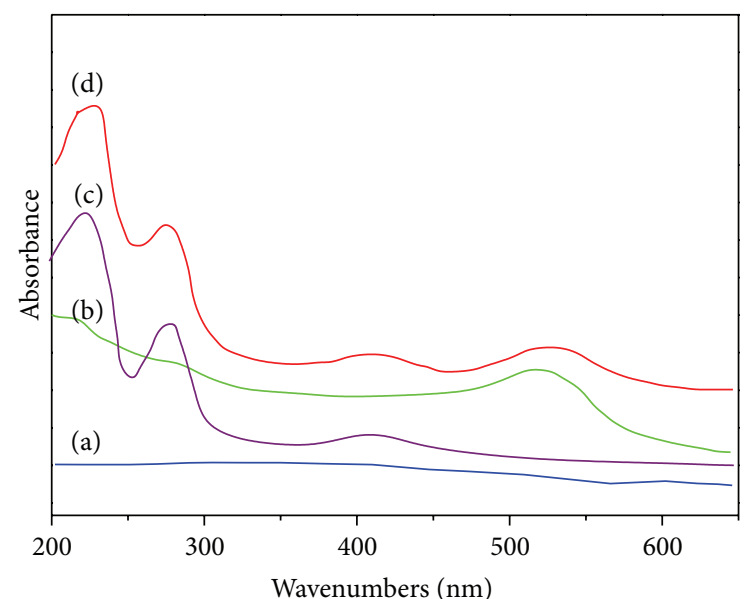

Figure 5: UV-Vis absorption spectrum of (a) $\mathrm{Fe}_{3} \mathrm{O}_{4} @ \mathrm{SiO}_{2}$, (b) $\mathrm{Fe}_{3} \mathrm{O}_{4} @ \mathrm{SiO}_{2} @ \mathrm{Au}$, (c) anti-CRP2/HRP, (d) Fe-Au MNPs-antiCRP2/HRP conjugation.

TABLE 1: Comparison of CRP levels in patient human serum samples $(n=3)$ determined using two methods.

\begin{tabular}{lcc}
\hline Serum samples & $\begin{array}{c}\text { The developed method } \\
\text { concentration }\left(\mathrm{ng} \cdot \mathrm{mL}^{-1}\right)\end{array}$ & $\begin{array}{c}\text { The classical ELIAS } \\
\text { concentration }\left(\mathrm{ng} \cdot \mathrm{mL}^{-1}\right)\end{array}$ \\
\hline Sample 1 & $8.12 \pm 0.21$ & 8.5 \\
Sample 2 & $5.31 \pm 0.41$ & 5.5 \\
Sample 3 & $21.1 \pm 0.22$ & 22 \\
Sample 4 & $1.1 \pm 0.03$ & $\mathrm{ND}$ \\
\hline
\end{tabular}

*ND: not detected.

detection, various biomarkers including carcinoma antigen 125 (CA 125), carcinoembryonic antigen (CEA), human IgG (HIgG), and prostate-specific antigen (PSA) were tested. The electrochemical signals were recorded in $10 \mathrm{ng} / \mathrm{mL}$ CRP with and without the interfering agents. No significant difference of currents was observed in comparison with the result obtained in the presence of only CRP, indicating

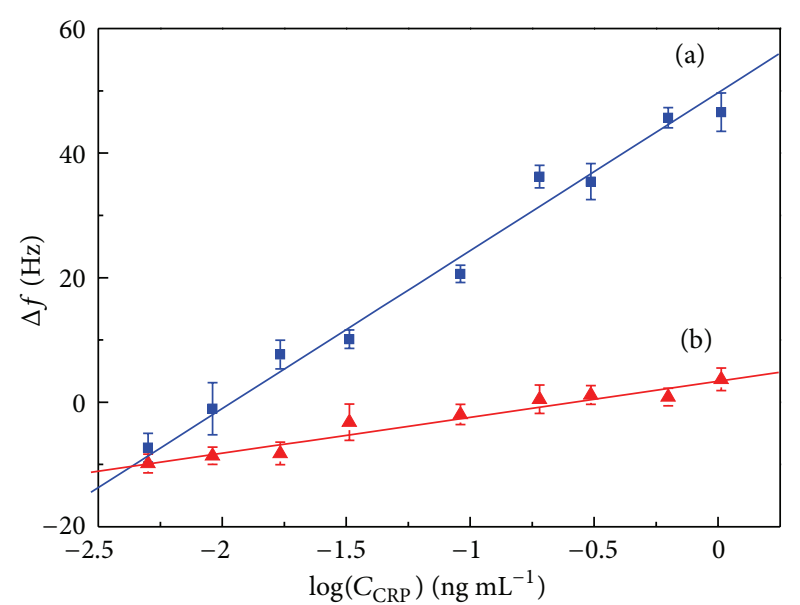

FIGURE 6: The calibration curve of the immunosensor with (a) Fe-Au MNPs-anti-CRP2/HRP and (b) HRP-anti-CRP2 signal tag.

that the specificity of the proposed electrochemical ELISA was acceptable. The reproducibility of the immunoassay was evaluated by using the coefficients of variation of intraassays and interassays. Taking $10 \mathrm{ng} \cdot \mathrm{mL}^{-1} \mathrm{CRP}$ for example, the intra-assays and interassays of the electrochemical were evaluated using one electrochemical ELISA for five repeat assays and five copies of electrochemical ELISA for one time assay. The coefficients of variation of the intra-assay and interassay were $3.4 \%$ and $2.4 \%$, respectively. Thus, the reproducibility of the electrochemical ELISA is satisfactory. The stability of the synthesized nanobioconjugate of $\mathrm{Fe}-\mathrm{Au}$ MNPs-anti-CPR2/HRP was also examined. When not in use, it could be stored in pH 7.0 PBS for at least 2 weeks without obvious signal change. Moreover, it retained $94.2 \%$ of its initial response after a storage period of 3 weeks. The slow decrease in the current response may be attributed to the gradual deactivation of the immobilized biomolecules on the surface of the nanoparticles.

3.6. Determination of CRP in Human Serum Samples. In order to investigate the possibility of the developed method for clinical analysis, some of patient human serum samples were examined by the developed method and the results were compared with the classical ELISA method. The concentration of CRP in three samples was determined to be consistent with the results obtained by the classical ELISA method (Table 1), indicating that the proposed immunoassay could be satisfactorily applied to the clinical determination of CRP. In Table 1, comparison of CRP levels in patient human serum samples $(n=3)$ was determined using two methods.

\section{Conclusions}

In this study, an ultrasensitive electrochemical immunoassay was developed for the detection of CRP in serum by using a newly designed magnetic HRP-labeled signal tag. The synergistic applications of $\mathrm{Fe}_{3} \mathrm{O}_{4} @ \mathrm{SiO}_{2} @ \mathrm{Au}$ nanoparticles and HRP labeled anti-CRP antibodies have been verified to well 


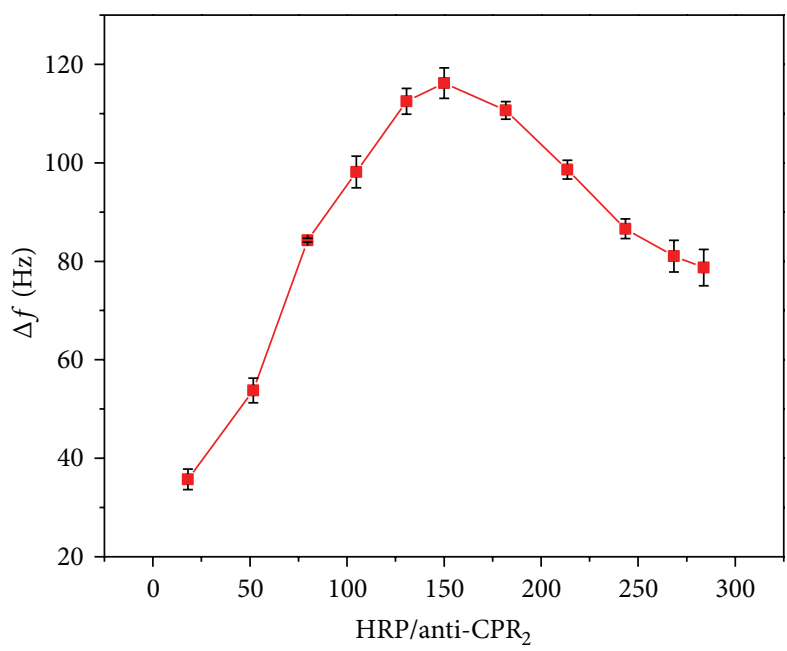

(a)

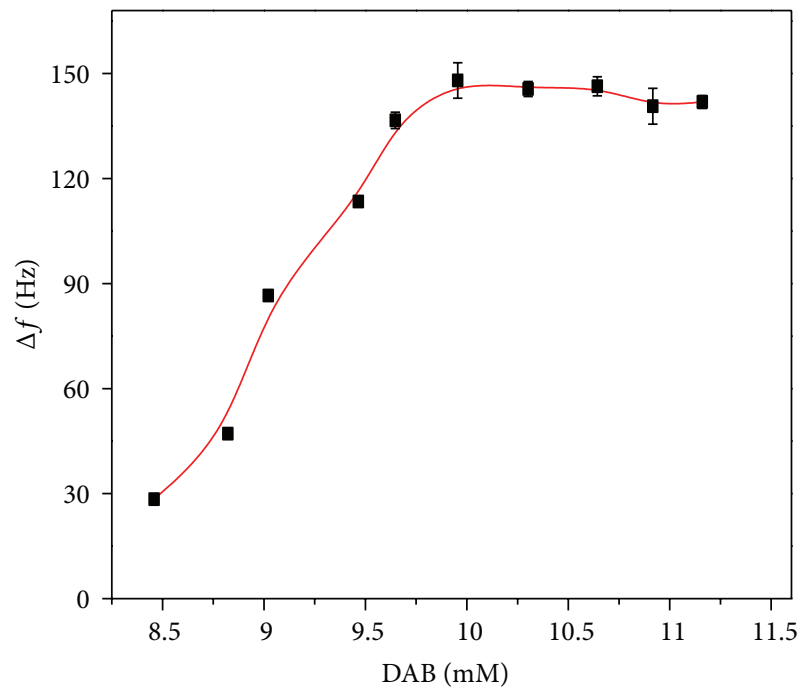

(c)

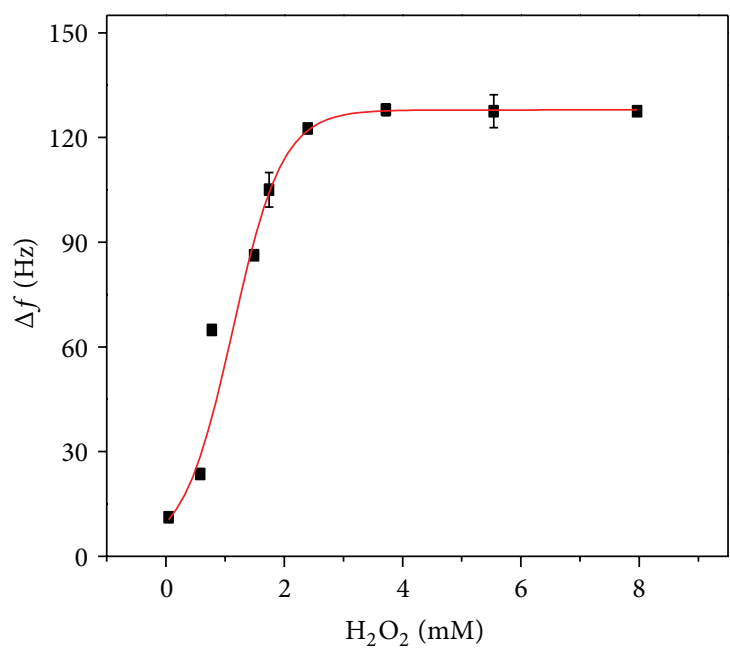

(b)

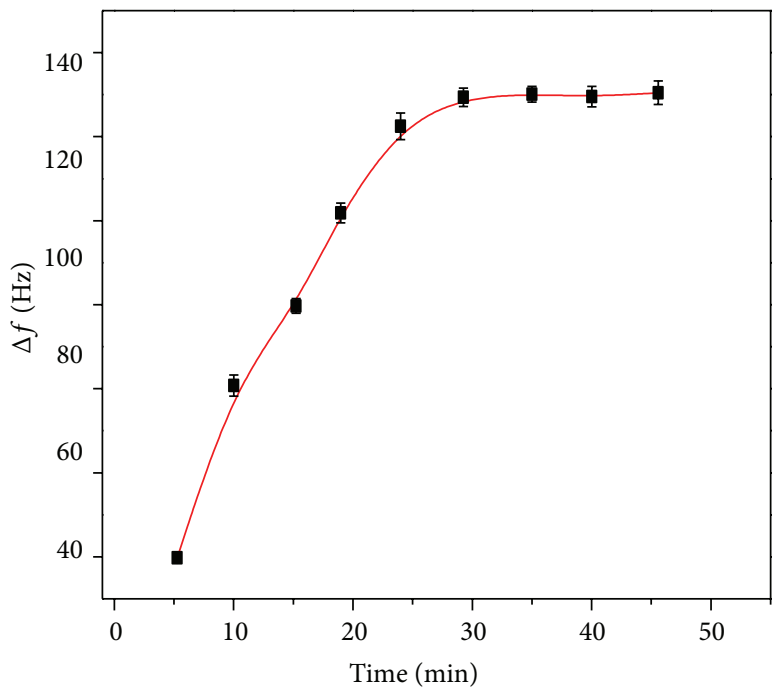

(d)

FIGURE 7: (a) Optimization of volume ratio of HRP to anti-CRP2 for preparation of Fe-Au MNPs-anti-CRP2/HRP. Effects of concentration of (b) $\mathrm{H}_{2} \mathrm{O}_{2}$, (c) DAB, and (d) incubation time on the signal response at the immunosensor.

circumvent the specific recognition of targeting CRP. $\mathrm{H}_{2} \mathrm{O}_{2}$ oxidization of the DAB substrate by HRP catalysis could produce an insoluble precipitation on the crystal resulting in greatly amplified QCM responses. The $\mathrm{Fe}_{3} \mathrm{O}_{4} @ \mathrm{SiO}_{2} @ \mathrm{Au}$ nanoparticle can provide a larger surface area for loading the enzyme-catalytic product in addition to serving as the selective sorbents. Moreover, DAB was verified as the ideal chromogenic substrate suitable for enzyme-catalytic precipitation. Ultrasensitive quantitative and rapid qualitative QCM analysis of the targets was achieved. This proposed QCM immunoassay is simple, of real-time, sensitive, and field applicable, holding great promise of being applied as an alternative tool for screening the concentration of CRP in CAD.

\section{Acknowledgments}

This work was supported by the National Natural Science Foundation of China (no. 30901367), the Natural Science Foundation of Zhejiang province and Ningbo (LY12C20004, 2012C23101, 2011C50038, Y3110479, 2011C23126, 2012A610144, and 2009R50025), and the K.C. Wong Magna Fund in Ningbo University, Science and Technology Planning Project of Guangdong Province (no. 2010A030300006).

\section{References}

[1] H. C. McGill, C. A. McMahan, A. W. Zieske et al., "Associations of coronary heart disease risk factors with the intermediate 
lesion of atherosclerosis in youth," Arteriosclerosis, Thrombosis, and Vascular Biology, vol. 20, no. 8, pp. 1998-2004, 2000.

[2] S. Kaptoge, E. Di Angelantonio, G. Lowe et al., "C-reactive protein concentration and risk of coronary heart disease, stroke, and mortality: an individual participant meta-analysis," The Lancet, vol. 375, no. 9709, pp. 132-140, 2010.

[3] I. Swiatkiewicz, M. Kozinski, P. Magielski et al., "Usefulness of C-reactive protein as a marker of early post-infarct left ventricular systolic dysfunction," Inflammation Research, vol. 61, no. 7, pp. 725-734, 2012.

[4] R. J. Bisoendial, S. M. Boekholdt, M. Vergeer, E. S. G. Stroes, and J. J. P. Kastelein, "C-reactive protein is a mediator of cardiovascular disease," European Heart Journal, vol. 31, no. 17, pp. 2087-2095, 2010.

[5] J. Danesh and M. B. Pepys, "Editorial: C-reactive protein and coronary disease: is there a causal link?" Circulation, vol. 120, no. 21, pp. 2036-2039, 2009.

[6] A. Johnson, Q. F. Song, P. K. Ferrigno, P. R. Bueno, and J. J. Davis, "Davis Sensitive affimer and antibody based impedimetric label-free assays for C-reactive protein," Analytical Chemistry, vol. 84, no. 15, pp. 6553-6560, 2012.

[7] D. Kumar and B. B. Prasad, "Multiwalled carbon nanotubes embedded molecularly imprinted polymer-modified screen printed carbon electrode for the quantitative analysis of Creactive protein," Sensors and Actuators B: Chemical, vol. 171-172, pp. 1141-1150, 2012.

[8] K. B. Male, S. Hrapovic, and J. H. T. Luong, "Electrochemicallyassisted deposition of oxidases on platinum nanoparticle/multiwalled carbon nanotube-modified electrodes," Analyst, vol. 132, no. 12, pp. 1254-1261, 2007.

[9] G. Z. Sauerbrey, "Use of quartz vibration for weighing thin films on a microbalance," Physik Journal, vol. 155, pp. 206-212, 1959.

[10] X. J. Chen, Y. Y. Wang, J. J. Zhou, W. Yan, X. H. Li, and J. J. Zhu, "Electrochemical impedance immunosensor based on three-dimensionally ordered macroporous gold film," Analytical Chemistry, vol. 80, pp. 2133-2140, 2008.

[11] J. W. Park, S. Kurosawa, H. Aizawa, Y. Goda, M. Takai, and K. Ishihara, "Piezoelectric immunosensor for bisphenol A based on signal enhancing step with 2-methacrolyloxyethyl phosphorylcholine polymeric nanoparticle," Analyst, vol. 131, no. 1, pp. 155-162, 2006.

[12] Y. Uludağ and I. E. Tothill, "Development of a sensitive detection method of cancer biomarkers in human serum (75\%) using a quartz crystal microbalance sensor and nanoparticles amplification system," Talanta, vol. 82, no. 1, pp. 277-282, 2010.

[13] T. Fu, H. Wang, G. L. Shen, and R. Q. Yu, "An amplified piezoelectric immunosensor based on amplification of enzymecatalyzed precipitation mass," Chemical Journal of Chinese Universities, vol. 27, no. 6, pp. 1032-1035, 2006.

[14] H. Wang, J. Wang, D. Choi, Z. Tang, H. Wu, and Y. Lin, "EQCM immunoassay for phosphorylated acetylcholinesterase as a biomarker for organophosphate exposures based on selective zirconia adsorption and enzyme-catalytic precipitation," Biosensors and Bioelectronics, vol. 24, no. 8, pp. 2377-2383, 2009.

[15] D. Tang, Q. Li, J. Tang, B. Su, and G. Chen, "An enzymefree quartz crystal microbalance biosensor for sensitive glucose detection in biological fluids based on glucose/dextran displacement approach," Analytica Chimica Acta, vol. 686, no. 1-2, pp. 144-149, 2011.

[16] F. Magni, Y. E. van der Burgt, C. Chinello et al., "Biomarkers discovery by peptide and protein profiling in biological fluids based on functionalized magnetic beads purification and mass spectrometry," Blood Transfusion, vol. 8, supplement 3, pp. 9297, 2010.

[17] J. Wang, H. Y. Han, X. C. Jiang, L. Huang, L. Chen, and N. Li, "Quantum dot-based near-infrared electrochemiluminescent immunosensor with gold nanoparticle-graphene nanosheet hybrids and silica nanospheres double-assisted signal amplification," Analytical Chemistry, vol. 84, no. 11, pp. 4893-4899, 2012.

[18] M. Hnaiein, W. M. Hassen, A. Abdelghani et al., "A conductometric immunosensor based on functionalized magnetite nanoparticles for E. coli detection," Electrochemistry Communications, vol. 10, no. 8, pp. 1152-1154, 2008.

[19] X. Wang, S. Huang, Z. Shan, and W. Yang, "Preparation of $\mathrm{Fe}_{3} \mathrm{O}_{4} @ \mathrm{Au}$ nano-composites by self-assembly technique for immobilization of glucose oxidase," Chinese Science Bulletin, vol. 54, no. 7, pp. 1176-1181, 2009.

[20] C. W. Lai, Y. H. Wang, C. H. Lai et al., "Iridium-complex-functionalized $\mathrm{Fe}_{3} \mathrm{O}_{4} / \mathrm{SiO}_{2}$ core/shell nanoparticles: a facile threein-one system in magnetic resonance imaging, luminescence imaging, and photodynamic therapy," Small, vol. 4, no. 2, pp. 218-224, 2008.

[21] N. Gan, H. J. Jin, T. H. Li, and L. Zheng, " $\mathrm{Fe}_{3} \mathrm{O}_{4} / \mathrm{Au}$ magnetic nanoparticle amplifcation strategies for ultrasensitive electrochemical immunoassay of alfa-fetoprotein," International Journal of Nanomedicine, vol. 6, pp. 3259-3269, 2011.

[22] V.-L. Inger and M. A. Willem, "Site-directed immobilisation of antibody fragments for detection of C-reactiveprotein," Biosensors and Bioelectronics, vol. 21, no. 7, pp. 1141-1148, 2006.

[23] G. J. Wolbink, M. C. Brouwer, S. Buysmann, I. J. M. Ten Berge, and C. E. Hack, "CRP-mediated activation of complement in vivo: assessment by measuring circulating complement-Creactive protein complexes," Journal of Immunology, vol. 157, no. 1, pp. 473-479, 1996.

[24] I. Levan-Petit, J. Cardonna, M. Garcia et al., "Sensitive ELISA for human immunoglobulin D measurement in neonate, infant, and adult sera," Clinical Chemistry, vol. 46, no. 6, pp. 876-878, 2000. 

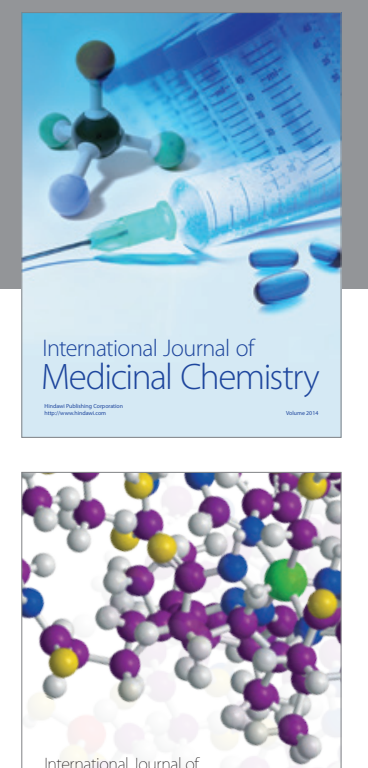

\section{Carbohydrate} Chemistry

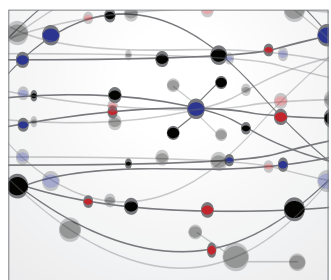

The Scientific World Journal
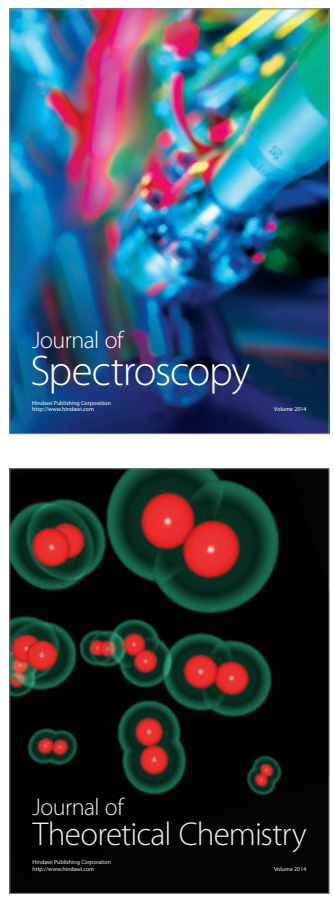
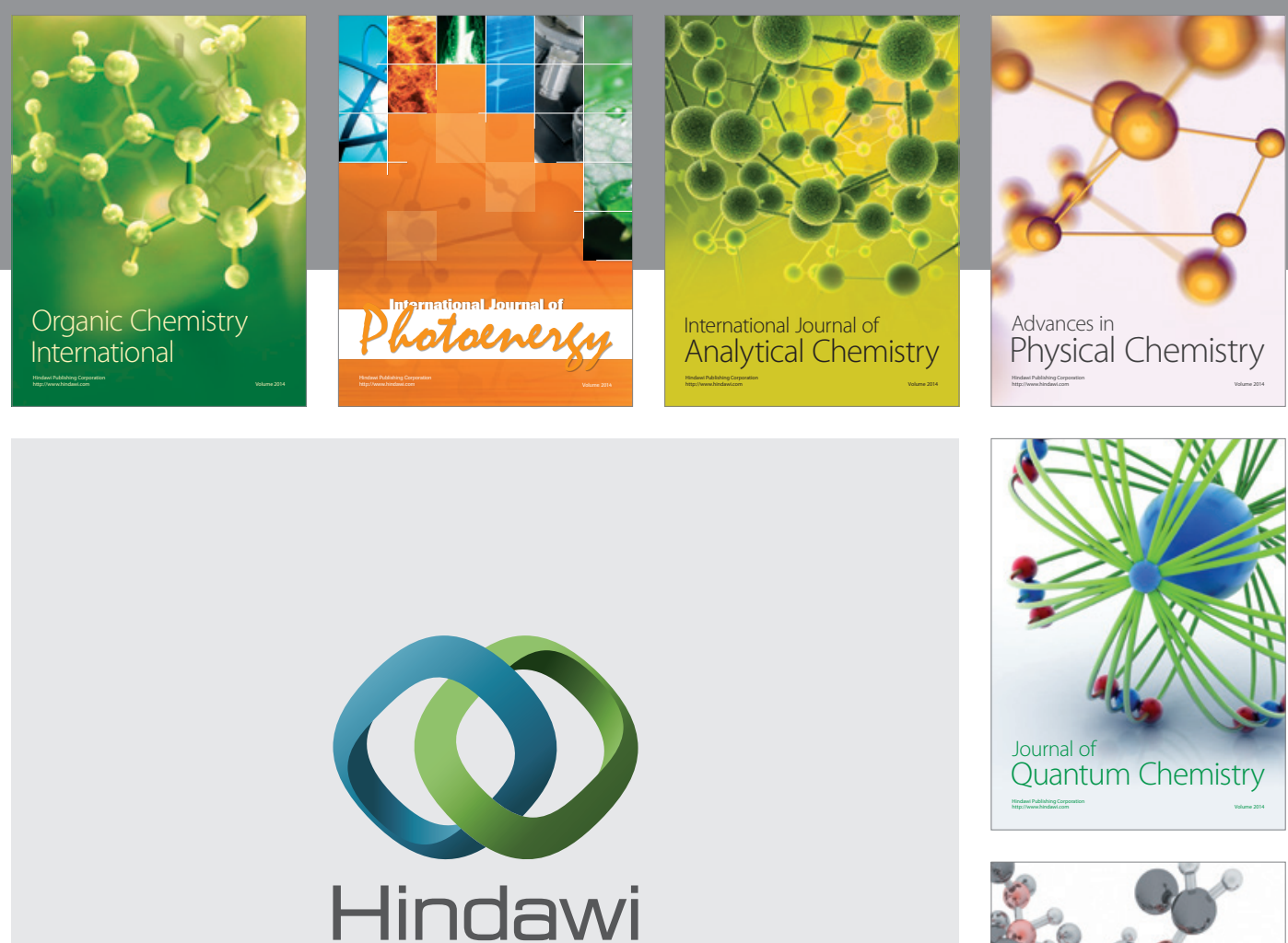

Submit your manuscripts at

http://www.hindawi.com

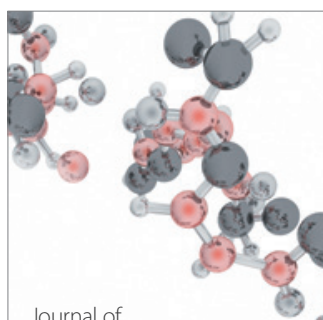

Analytical Methods

in Chemistry

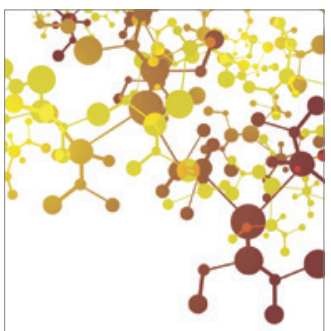

Journal of

Applied Chemistry

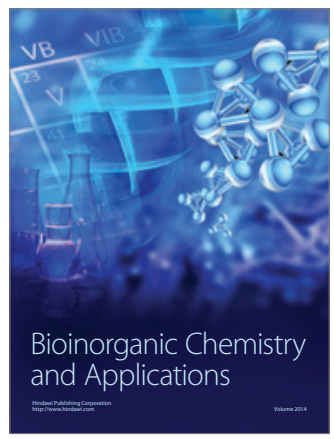

Inorganic Chemistry
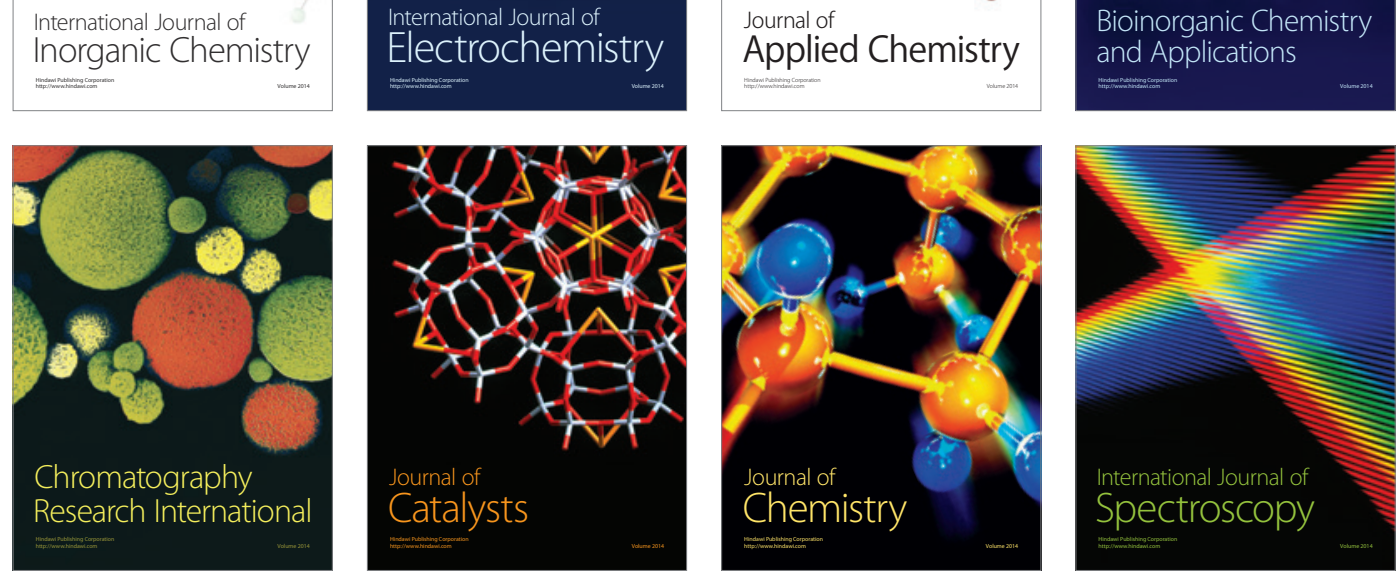